\title{
Opioid Peptide Immunoreactivity in Spinal and Trigeminal Dorsal Horn Neurons Projecting to the Parabrachial Nucleus in the Rat
}

\author{
David G. Standaert, ${ }^{\star}$ Stanley J. Watson, $†$ Richard A. Houghten, $\ddagger$ and Clifford B. Saper** \\ *Departments of Neurology and Neurological Surgery (Neurology) and Anatomy and Neurobiology, \\ Washington University School of Medicine, St. Louis, Missouri 63110, \\ †Mental Health Research Institute, University of Michigan, Ann Arbor, Michigan 48109, \\ $\$$ Scripps Clinic, Department of Molecular Biology, La Jolla, California 92137, and \\ **Departments of Pharmacological and Physiological Sciences and Neurology, and \\ Brain Research Institute, University of Chicago, Illinois 60637
}

The parabrachial nucleus (PB) is the major relay for ascending visceral afferent information from the nucleus of the solitary tract to the forebrain. We have recently found that $P B$ in the rat also receives a substantial afferent projection from neurons in the marginal zone of the entire length of the spinal and trigeminal dorsal horn. Immunoreactive perikarya stained with antisera against several neuropeptides-including dynorphin, enkephalins, and substance $P$-have been identified in the marginal zone. We therefore investigated the chemical specificity of the spinoparabrachial projection by combining fluorescent retrograde tracing with immunofluorescence for substance $P$, dynorphin A1-17, met-enkephalin, and two enkephalin precursor fragments (proenkephalin 192-203 and peptide E).

Following PB injections of fluorescent dyes, about half of the retrogradely labeled neurons in the marginal zone stained with antisera against either dynorphin or enkephalin series peptides. Elution-restaining experiments indicated that the dynorphinand enkephalin-immunoreactivities were contained within separate populations of marginal zone neurons. We could not identify any substance $P$-immunoreactive perikarya in the marginal zone, but substance P-immunoreactive fibers were seen in close apposition to retrogradely labeled, opioid-immunoreactive cell hodies and dendrites.

These results indicate that the dynorphin- and enkephalinimmunoreactive perikarya in the marginal zone of the dorsal horn represent independent neuronal populations. These opioidimmunoreactive neurons, which are believed to have extensive local collateral connections, are the main source of a long ascending projection to the parabrachial nucleus in the rat. Furthermore, opioid neurons in the marginal zone may receive substance P-immunoreactive primary sensory afferents.

The parabrachial nucleus $(\mathrm{PB})$ is an important relay for visceral afferent information traveling from the nucleus of the solitary tract to the forebrain. Early studies of ascending spinal cord pathways using anterograde degeneration after spinal lesions

\footnotetext{
Received Jan. 29, 1985; revised Oct. 15, 1985; accepted Oct. 15, 1985.

We thank Ms. Quan Hue Ha for technical assistance and Ms. Patti Nacci for typing the manuscript. The met-enkephalin antiserum was the generous gift of Dr. R. Elde. Supported by grants from USPHS NS18669 and N522835 (C.B.S.), NSI8113 (R.A.H.), and GM07200 (D.G.S.); from ADAMHA DA 02265 and MH 39717 (S.J.W.); and from the T. Raphael Research Fund (S.J.W.). C.B.S. is recipient of NINCDS Teacher-Investigator Development Award NS00631 and a McKnight Scholar Award.

Correspondence should be addressed to Dr. Saper, Department of Pharmacological and Physiological Sciences, University of Chicago, 947 East 58th Street, Chicago, IL 60637.

Copyright (C) 1986 Society for Neuroscience $0270-6474 / 86 / 051220-07 \$ 02.00 / 0$
}

demonstrated projections from the spinal cord to PB in several species (Mehler, 1962; Mehler et al. 1960; Zemlan et al., 1978). The spinoparabrachial projection has recently been examined in detail in the rat and the cat using the anterograde and retrograde transport of wheat germ agglutinin conjugated to horseradish peroxidase (WGA-HRP) (Cechetto et al., 1985; Panneton and Burton, 1985). Injections of WGA-HRP into PB retrogradely label large, flattened cells that lie parallel to the pial surface within the marginal zone of the dorsal horn, throughout the entire rostrocaudal extent of the spinal cord and spinal trigeminal nucleus pars caudalis. At the level of the obex, an additional group of retrogradely labeled neurons is seen among the fibers of the dorsal part of the spinal trigeminal tract in the promontorium $^{1}$ of the spinal trigeminal nucleus. Following injection of WGA-HRP into the marginal zone of the spinal cord, anterogradely labeled fibers can be seen innervating predominantly the lateral division of $\mathrm{PB}$, including the central, dorsal, and external lateral subnuclei and the Kolliker-Fuse nucleus. Injections of WGA-HRP into the promontorium and adjacent spinal trigeminal nucleus label fibers innervating these same subnuclei of lateral $\mathrm{PB}$, as well as the medial subdivision of $\mathrm{PB}$ (Cechetto et al., 1985; Fulwiler and Saper, 1984; Panneton and Burton, 1985).

Neurons in the outer lamina of the dorsal horn have been observed to stain immunohistochemically for a number of neuropeptides, including enkephalins (Aronin et al., 1981; Glazer and Basbaum, 1981), dynorphin (Khachaturian et al., 1982), and substance P (Del Fiacco and Cuello, 1980; DiFiglia et al., 1982; Ljungdahl et al., 1978). Immunohistochemical staining for all three of these peptides has been observed in fibers forming dense terminal fields in PB (Kawai et al., 1982; Khachaturian et al., 1982; Léger et al., 1983; Milner et al., 1984). Each of these peptides is therefore a candidate for the transmitter of the spinoparabrachial pathway.

In the present study, we have used a fluorescent retrograde neuronal tracer in combination with immunohistochemistry to investigate the peptides present in spinal and trigeminal neurons projecting to $\mathrm{PB}$. Our results demonstrate that most of the neurons in the spinal and trigeminal dorsal horns that project to PB contain either dynorphin- or enkephalin-like immunoreactive (-lir) material.

\footnotetext{
'Although the term "paratrigeminal nucleus" has also been used for this cell group (Chan-Palay, 1978; Panneton and Burton, 1985), Rhoton et al. (1966) earlier used this term to describe a group of cells lateral to the spinal trigeminal tract at the pontomedullary junction in the monkey. Because of this ambiguity, we prefer Astrom's (1953) term, "promontorium."
} 


\section{Materials and Methods}

\section{Retrograde transport-immunohistochemistry experiments}

Stereotaxic injections of $50 \mathrm{nl}$ of a $5 \%$ solution of Fast Blue dye (Illing) were made into the PB region of six Sprague-Dawley rats. Injections were made using a glass micropipette syringe (Saper, 1983) under chloral hydrate anesthesia. After 7-14 d survival, the rats were treated with $150 \mu \mathrm{g}$ colchicine (Sigma) in $10 \mu \mathrm{l}$ saline injected stereotaxically into the lateral ventricle. Between 24 and $48 \mathrm{hr}$ later, the rats were reanesthetized with chloral hydrate and perfused through the heart with saline followed by $4 \%$ paraformaldehyde in $0.1 \mathrm{M}$ phosphate buffer, $\mathrm{pH} 7.4$ The brains and spinal cords were removed, and the spinal cords were cut into blocks of three segments each. The brain stems were cut into $50 \mu \mathrm{m}$ sections using a freezing microtome. Twelve $50 \mu \mathrm{m}$ sections were cut from the rostral end of each spinal cord block. The pontine sections were mounted on slides and used to verify the injection site. The medullary and spinal cord sections were processed for immunohistochemistry.

Sections were incubated for $1 \mathrm{hr}$ in $0.1 \mathrm{M}$ phosphate buffer, $\mathrm{pH} 7.3-$ $0.9 \% \mathrm{NaCl}$ (PBS), containing $0.25 \%$ Triton $\mathrm{X}-100$, followed by $1 \mathrm{hr}$ in PBS containing 3\% goat serum (PBS-G). The sections were then divided into four groups of every fourth section. Each group of sections was incubated overnight at $4^{\circ} \mathrm{C}$ in PBS-G containing both substance $P$ antibody diluted 1:2000 or 1:4000, and one of the following sera: antidynorphin A1-17 (1:1000), anti-peptide E (1:300), anti-proenkephalin 192-203 (1:300), or anti-met-enkephalin (1:200). The next day, the sections were incubated for $1 \mathrm{hr}$ in fluoroscein isothiocyanate (FITC)labeled goat anti-rabbit serum (Miles; 1:50 in goat serum-PBS), washed several times in PBS-G, and incubated for an additional hour in rhodamine isothiocyanate (RITC)-labeled rabbit anti-mouse serum (Miles; 1:50 in PBS-G). The sections were then mounted on gelatin-coated slides and coverslipped with glycerin.

\section{Antibody elution experiments}

The elution-restaining technique of Tramu et al. (1978) was used to stain the same sections sequentially for two different opioid peptides. In all, six animals were used for these experiments. All were treated with $150 \mu \mathrm{g}$ of colchicine and perfused as described above. Sections from the medulla and spinal cord were incubated overnight in PBS-G containing substance $P$ antibody $(1: 4000)$ and either met-enkephalin or dynorphin A1-17 antisera as described above. The next day, these sections were incubated in PBS-G containing FITC-labeled goat anti-rabbit (Miles, 1:50) and RITC-labeled goat anti-rat (Cappel, 1:50) antisera for $1 \mathrm{hr}$. The sections were then coverslipped with a solution of PBS and glycerin (1:3).

After observing and photographing immunohistochemically stained neurons in the promontorium and dorsal horn, the coverslips were removed and the sections washed in PBS. Antibodies were eluted using a solution of $0.1 \% \mathrm{KMnO}_{4}$ and $0.20 \% \mathrm{H}_{2} \mathrm{SO}_{4}$ in distilled water for $5-$ $10 \mathrm{~min}$. After decolorizing in $0.5 \% \mathrm{NaH}_{2} \mathrm{SO}_{5}$ for $1 \mathrm{~min}$, the sections were incubated in FITC-labeled goat anti-rabbit serum for $30 \mathrm{~min}$, coverslipped with PBS-glycerin, and observed to ascertain that all staining had been eliminated. The coverslips were removed, and the sections were then washed in PBS and incubated overnight in a second opioid primary antiserum (i.e., sections that had been stained with anti-metenkephalin were incubated in anti-dynorphin, while sections stained with anti-dynorphin were incubated with anti-met-enkephalin). The next day, the sections were incubated for $1 \mathrm{hr}$ in FITC-labeled goat antirabbit serum. The sections were coverslipped with PBS-glycerine, and the new pattern of staining in the promontorium was compared with the photographs of the staining produced by the first antiserum.

\section{Antisera}

The methionine-enkephalin antiserum was obtained from Dr. R. Elde (\#R153e); the production and specificity of this serum have been described (Haber and Elde, 1982). The rat monoclonal substance $P$ antibody was obtained from Sera-lab (MAS 035). The preparation and specificity of this antibody have been described by Cuello et al. (1979).

Antisera to dynorphin Al-17 (\#54-B16), proenkephalin 192-203 (\#52B15), and peptide E (\#63-B16) were prepared (by S.J.W.) using antigens made by conjugating peptide $\mathrm{E}$, dynorphin $\mathrm{A} 1-17$, or bovine proenkephalin 192-203 (prepared by R.A.H.) to thyroglobulin using glutaraldehyde.

Specificity of the opioid antisera in our preparations was tested by preincubating the diluted serum with synthetic dynorphin A1-17 (Bachem), leu-enkephalin (Sigma), met-enkephalin (Sigma), or the proenkephalin 192-203 fragment at a concentration of $50 \mu \mathrm{g}$ peptide $/ \mathrm{ml}$ of diluted serum.

The specificity of the substance $P$ antibody was tested by adsorption with $50 \mu \mathrm{g}$ of synthetic substance P (Sigma) per milliliter of diluted antibody.

\section{Results}

\section{Retrograde transport-immunohistochemistry experiments}

In all six rats, large deposits of Fast Blue dye were seen in the $\mathrm{PB}$ region. The injection sites included both the medial and lateral PB subnuclei, as well as the Kolliker-Fuse nucleus, the locus ceruleus, and the mesencephalic and principal sensory trigeminal nuclei. Retrogradely labeled cell bodies were observed in the promontorium, as well as throughout lamina I of the spinal and trigeminal dorsal horns, bilaterally. As described in our previous study, this pattern of retrograde labeling is produced only by injections involving $\mathrm{PB}$, and not by injections into adjacent structures (Cechetto et al., 1985).

Cells containing dynorphin-, met-enkephalin-, peptide E-, and proenkephalin-lir were found in the trigeminal promontorium and throughout the marginal zone of the spinal and trigeminal dorsal horn. All four of the antisera stained populations of neurons that were similar in appearance and distribution to the cells of origin of the spinoparabrachial projection. Many of the opioid cells were also labeled with the retrograde tracer. Because of the light immunohistochemical staining of some of the cell bodies, and heavy staining of many fibers in the same region, it was not possible to determine exactly what proportion of the cells containing the retrograde tracer were immunohistochemically labeled. However, in some cases as many as half of the cells in the marginal zone and promontorium that contained Fast Blue also stained with either dynorphin, met-enkephalin, proenkephalin, or peptide E antisera (Figs. 1, 2).

In the spinal cord, control incubations using met-enkephalin and dynorphin antisera preadsorbed with synthetic dynorphin or met-enkephalin showed that each peptide blocked the appropriate antiserum and did not affect the other. Neither antiserum was affected by synthetic leu-enkephalin. The proenkephalin staining was not affected by dynorphin, met-enkephalin, or leu-enkephalin, but was completely blocked by proenkephalin 192-203. The peptide E staining was blocked by dynorphin and met- and leu-enkephalin.

Substance P-lir fibers were found to innervate the promontorium and the outer lamina of the spinal trigeminal nucleus and spinal dorsal horn, as has been reported by other investigators (Barber et al., 1979; Del Fiacco and Cuello, 1980). No unequivocal substance P-lir cell bodies were observed within the dorsal horn, although the intense fiber staining that persisted despite colchicine treatment might have made cell bodies difficult to distinguish. A notable feature of the substance P-staining was the relationship between the substance P-lir fibers and opioid-lir cells. Substance P-lir fibers were observed surrounding and outlining individual cell bodies stained with dynorphin, met-enkephalin, proenkephalin, or peptide $\mathrm{E}$ antisera; many of these also contained the retrograde tracer (Fig. $1, C$ and $D$ ). This relationship was most conspicuous in the promontorium, while in the spinal cord the substance P-lir fiber staining was so intense that it was only rarely possible to discern a relationship between individual fibers and cells.

All substance $P$ immunohistochemical staining was abolished by pre-incubating the antibody with synthetic substance $P$. The patterns of staining demonstrated using RITC-labeled anti-rat IgG produced in rabbit (retrograde transport experiments) or in goat (elution experiments) were identical. Using either method, substance P-lir fibers were found in close association with opioid- 

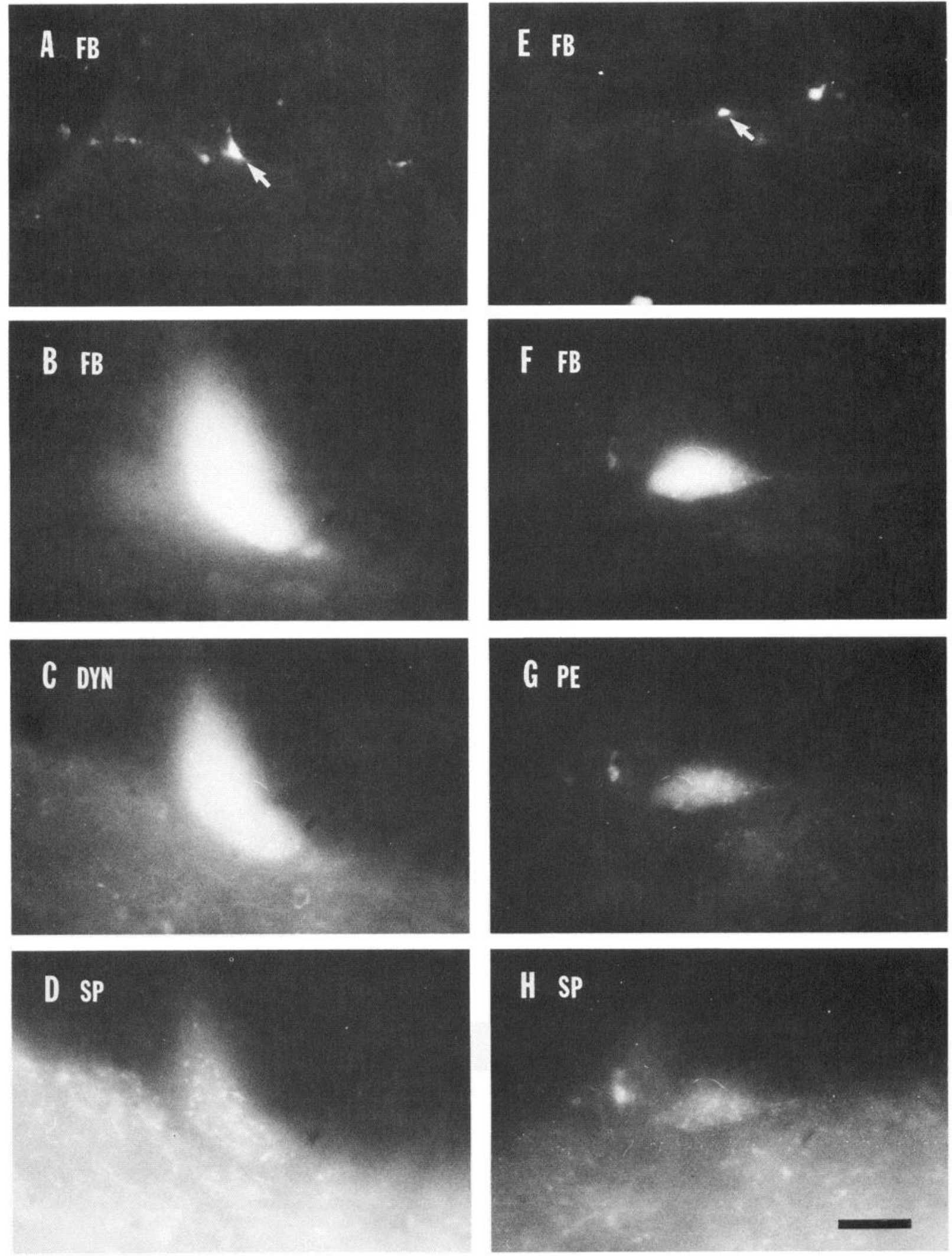

Figure 1. Fluorescence photomicrographs of neurons in the dorsal horn of the spinal cord. $A$, Low-power view of retrograde label in dorsal horn at $C 8$ level. Arrow indicates cell shown at higher magnification in $B-D$. $B$, Fast Blue retrograde label; $C$, dynorphin-like immunoreactivity(-lir); $D$, substance P-lir. $E$, Retrograde label in the dorsal horn at T5 level. $F-H$, Same cell at higher magnification; $F$, Fast Blue; $G$, peptide E-lir; $H$, substance P-lir. Note the punctate appearance of substance P-lir staining around these two cells. Scale bar: $A$ and $E, 100 \mu \mathrm{m} ; B-D$ and $F-H$, $10 \mu \mathrm{m}$. 

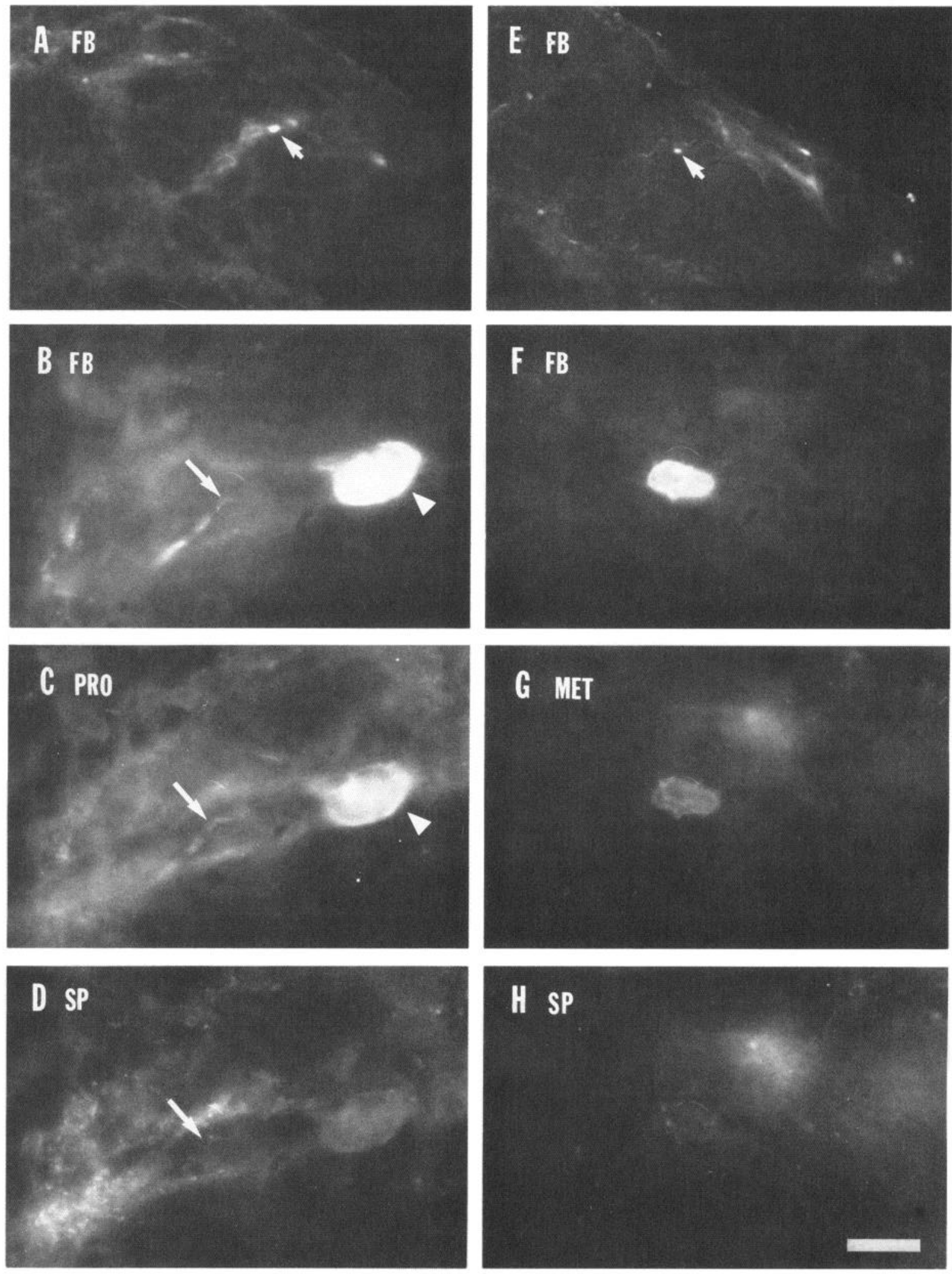

Figure 2. Fluorescence photomicrographs of neurons in two sections through the promontorium of the spinal trigeminal tract. $A$ and $E$, Lowpower view of Fast Blue retrograde labeling shown at higher power in $B$ and $F$, respectively; $C$, proenkephalin-lir; $G$, met-enkephalin-lir; $D$ and $H$, substance P-lir. Note that the retrogradely labeled dendrite (arrow) in $B$ stained immunohistochemically for proenkephalin $192-203$ (C). This process was also invested with substance P-lir terminals $(D)$. By focusing through the section, it was apparent that this cell body was continuous with the proenkephalin-lir retrogradely labeled cell body (arrowhead) in $C$. Note that a few substance P-lir terminals were also visualized adjacent to the met-enkephalin-lir, retrogradely labeled neuron shown in $F$ and $G$. Scale, as in Figure 1 . 

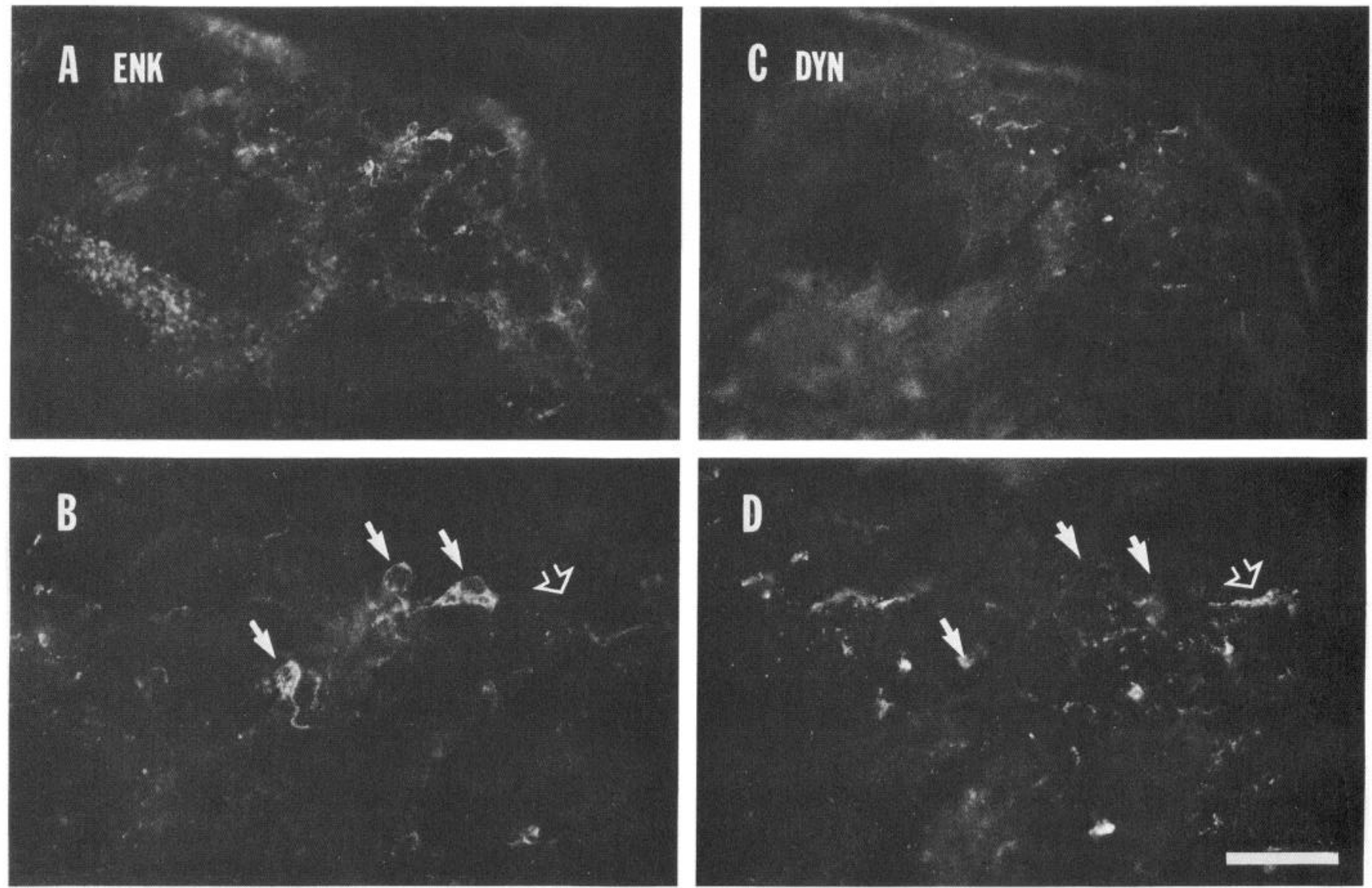

Figure 3. Photomicrographs of a section through the promontorium stained sequentially for enkephalin- and dynorphin-lir. A, Low-power view of section stained for met-enkephalin-lir. B, Same section at higher magnification. Solid arrows identify three enkephalin-lir neurons. $C$, Same section, after elution of antibodies, stained for dynorphin-lir. D, Higher magnification showing that the three enkephalin-lir neurons (solid arrows) are not stained by dynorphin antiserum. Open arrow identifies a dynorphin-lir neuron that is not stained for enkephalin-lir. Scale bar: $A$ and $C$, $125 \mu \mathrm{m} ; B$ and $D, 50 \mu \mathrm{m}$.

staining neurons. Neither method revealed any single structure stained simultaneously for substance $\mathrm{P}$ and one of the opioids. These observations demonstrate that both of these methods are capable of simultaneous independent localization of two different peptides.

\section{Elution experiments}

As both the dynorphin and enkephalin family antisera stained similar-appearing populations of lamina I dorsal horn neurons, we attempted to determine whether the antisera were staining the same cells. Using the elution technique of Tramu et al. (1978) as described, we were able to stain sections sequentially for enkephalin and dynorphin. We found a large number of promontorium and dorsal horn cells that stained for each of these two peptides, but no examples were seen of cells that stained for both antisera (Fig. 3).

\section{Discussion}

In a previous report we described a pathway that arises from neurons in the marginal zone of the spinal and trigeminal dorsal horns and terminates in PB. The present experiments demonstrate that the cells of origin of this pathway can be stained immunohistochemically using antisera to peptides in the dynorphin and enkephalin families. Furthermore, we have presented evidence suggesting that enkephalin- and dynorphin-lir are present within separate populations of neurons.

The retrograde tracer used in this study, Fast Blue, has two inherent disadvantages: the injection sites are quite large, and the dye may be picked up by fibers of passage. As a result, in studies using this tracer alone, it is not possible to determine precisely where the axons of retrogradely labeled neurons terminate. Fortunately, in our earlier study on the spinoparabrachial projection, we established that none of the structures adjacent to PB that might have been included in the Fast Blue injection sites receive projections from the marginal zone of the dorsal horn. The one spinal pathway that passes through this region, the ventral spinocerebellar tract, does not arise from neurons in the marginal zone of the dorsal horn in the rat (Matsushita and Hosoya, 1979; Snyder et al., 1978). Furthermore, the retrogradely labeled neurons observed in this study were essentially identical both in number and distribution to the spinoparabrachial neurons described in our earlier study using WGA-HRP, a tracer that is not picked up by fibers of passage (Brodal et al., 1983; Shook et al., 1984). We therefore conclude that the retrogradely labeled neurons in the promontorium and in lamina $I$ of the spinal and trigeminal dorsal horn in these experiments actually innervate $\mathrm{PB}$.

The antisera we used in this study appear to stain separate populations of enkephalin and dynorphin neurons in the paraventricular nucleus of the hypothalamus (Watson et al., 1982). The results of our elution experiments suggest that the same is true of neurons in the promontorium and dorsal horn. This finding is in agreement with the recent report of Guthrie and Basbaum (1984; and personal communication). In individual retrograde tracing experiments, we found that as many as half of the retrogradely labeled promontorium and dorsal horn neu- 
rons stained for each of the opioid peptides. If these peptides are, in fact, contained in separate populations of neurons, then most, if not all, of the spinoparabrachial neurons must contain opioid peptides.

We have observed that many of the opioid-lir neurons of the dorsal horn that project to PB are surrounded by dense networks of substance P-lir fibers. While it is not possible to determine by light microscopy whether synaptic contacts are made, the pattern of varicosities observed surrounding the opioid neurons is highly suggestive of interaction between these fibers and the opioid cells. Previous investigators have commented on the close association of substance P-lir fibers and enkephalin-lir neurons in the spinal dorsal horn. However, it has proved quite difficult to demonstrate synaptic contact between these elements, leading to the hypothesis of "nonsynaptic" interactions (Cucllo, 1983).

The antibody used to stain these fibers was raised against substance $P$, but it is important to note that substance $P$ is only one of a family of neuropeptides, the tachykinins, that also includes substance $\mathrm{K}$ and neuromedin $\mathrm{K}$. These peptides all share a common C-terminal sequence, and all three are thought to be present in mammalian CNS (Harmar, 1984). The monoclonal substance $\mathrm{P}$ antibody used in this investigation probably cross-reacts with all of these peptides (J. Maggio, personal communication). Therefore, although we refer to the staining as substance P-lir, the actual peptide contained in these fibers remains unknown.

Most of the enkephalin-lir neurons in the dorsal horn are thought to be interneurons, and there is considerable evidence that opioid peptides can regulate the release of substance $P$ from primary sensory afferents (see Jessel, 1983, for review). This interaction has been interpreted as a mechanism for modulating the transmission of nociceptive information. Our results indicate that many of the neurons in the dorsal horn that stain for opioid peptides have long ascending projections to $\mathrm{PB}$. Whether enkephalin-lir terminals in the dorsal horn are collaterals of spinoparabrachial axons or arise from a second population of enkephalin-lir interneurons remains to be determined. However, many of the large, flattened lamina I neurons that receive nociceptive afferents have both local recurrent and long ascending axon collaterals (Bennett et al., 1980; Brown, 1982; Light et al., 1979; Woolf and Fitzgerald, 1983). Opioid neurons in the dorsal horn may therefore be involved both in local transmission of nociceptive information, as well as in regulating autonomic responses to painful stimuli by means of their input to $\mathrm{PB}$.

An alternate hypothesis is suggested by the observation that neonatal capsaicin treatment eliminates substance P-lir fibers in the dorsal horn and promontorium. This has been taken to imply that the substance P-lir innervation of the dorsal horn is involved in chemosensory transmission (Janscó and Király, 1980). There is evidence that chemosensory afferents from muscle that terminate in the outer lamina of the dorsal horn mediate vasopressor responses to exercise through a spinobulbospinal pathway (Mitchell et al., 1983). The role of the spinoparabrachial projection in autonomic regulation is not known, but the pathway innervates regions of $P B$ that have been implicated in cardiovascular control (Cechetto et al., 1985; Fulwiler and Saper, 1984; Hamilton et al., 1981; Mraovitch et al., 1982). These observations suggest that the opioid spinal projection to PB should be a fruitful area for further study of spinal-cardiovascular reflexes.

\section{References}

Aronin, N., M. DiFiglia, A. Liotta, and J. B. Martin (1981) Ultrastructural localization and biochemical features of immunoreactive leu-enkephalin in monkey dorsal horm. J. Neurusci. 1: 561-577.

Astrom, K. E. (1953) On the central course of afferent fibers in the trigeminal, facial, glossopharyngeal, and vagal nerves and their nuclei in the mouse. Acta Physiol. Scand. (Suppl. 6) 29: 209-320.

Barber, R. P., J. E. Vaughn, J. R. Slemmon, P. M. Salvaterra, E. Roberts, and S. E. Leeman (1979) The origin, distribution, and synaptic relationships of substance $P$ axons in rat spinal cord. J. Comp. Neurol. 184: 331-352.

Bennett, G., M. Abdelmoumene, H. Hayashi, and R. Dubner (1980) Physiology and morphology of substantia gelatinosa neurons intracellularly stained with horseradish peroxidase. J. Comp. Neurol. 194: 809-827.

Brodal, P., E. Dietrichs, J. G. Bjaalie, T. Nordby, and F. Walberg (1983) Is lectin-coupled horseradish peroxidase taken up and transported by undamaged as well as by damaged fibers in the central nervous system? Brain Res. 278: 1-9.

Brown, A. G. (1982) Dorsal horn of the spinal cord. Q. J. Exp. Physiol. 67: 193-212.

Cechetto, D. F., D. G. Standaert, and C. B. Saper (1985) Spinal and trigeminal dorsal horn projections to the parabrachial nucleus in the rat. J. Comp. Neurol. 240: 153-160.

Chan-Palay, V. (1978) The paratrigeminal nucleus: I. Neurons and synaptic organization. J. Neurocytol. 7: 405-418.

Cuello, A. C. (1983) Central distribution of opioid peptides. Br. Med. Bull. 39: 11-16.

Cuello, A. C., G. Galfre, and C. Milstein (1979) Detection of substance $P$ in the central nervous system by a monoclonal antibody. Proc. Natl. Acad. Sci. USA 76: 3532-3536.

Del Fiacco, M., and A. C. Cuello (1980) Substance P-and enkephalincontaining neurons in the rat trigeminal system. Neuroscience 5:803815.

DiFiglia, M., N. Aronin, and S. E. Leeman (1982) Light microscopic and ultrastructural localization of substance $P$ in the dorsal horn of the monkey spinal cord. Neuroscience 7: 1127-1139.

Fulwiler, C. E., and C. B. Saper (1984) Subnuclear organization of the efferent connections of the parabrachial nucleus in the rat. Brain Res. Rev. 7: 229-259.

Glazer, E., and A. Basbaum (1981) Immunohistochemical localization of leu-enkephalin in the spinal cord of the cat: Enkephalin-containing marginal neurons and pain modulation. J. Comp. Neurol. 196: 377389.

Guthrie, J., and A. Basbaum (1984) Colocalization of immunoreactive proenkephalin and prodynorphin products in medullary neurons of the rat. Neuropeptides 4: 437-445.

Haber, S., and R. Elde (1982) The distribution of enkephalin immunoreactive terminals in the monkey central nervous system: An immunohistochemical study. Neuroscience 7: 1049-1095.

Hamilton, R. B., H. Ellenberger, D. Liskowsky, and N. Schneiderman (1981) Parabrachial area as mediator of bradycardia in rabbits. $J$. Autonom. Nerv. System 4: 261-281.

Harmar, A. J. (1984) Three tachykinins in mammalian brain. Trends Neurosci. 7: 57-60.

Janscó, G., and E. Király (1980) Distribution of chemosensitive primary sensory afferents in the central nervous system of the rat. $J$. Comp. Neurol. 190: 781-792.

Jessel, T. (1983) Nociception. In Brain Peptides, D. T. Krieger, M. J. Brownstein, and J. B. Martin, eds., pp. 315-332, Wiley-Interscience, New York.

Kawai, Y., S. Inagaki, S. Shiosaka, E. Senba, K. Takatsuki, M. Sakanaka, K. Umegaki, and M. Tohyama (1982) Multiple innervation by substance P-containing fibers in the parabrachial area of the rat. Neurosci. Lett. 33: 271-274.

Khachaturian, H., S. J. Watson, M. E. Lewis, D. Coy, A. Goldstein, and $H$. Akil (1982) Dynorphin immunocytochemistry in the rat central nervous system. Peptides 3: 941-954.

Leǵer, L., Y. Charnay, J. A. Chayvialle, A. Bérod, F. Dray, J. F. Pujol, M. Jouvet, and P. M. Dubois (1983) Localization of substance P. and enkephalin-like immunoreactivity in relation to catecholaminecontaining cell bodies in the cat dorsolateral pontine tegmentum: An immunofluorescence study. Neuroscience $8: 525-546$.

Light, A. R., D. L. Trevino, and E. R. Perl (1979) Morphologic features of functionally defined neurons in the marginal zone and substantia gelatinosa of the spinal dorsal horn. J. Comp. Ncurol. 186: 151-172.

Ljungdahl, A., T. Hökfelt, and G. Nilson (1978) Distribution of substance P-like immunoreactivity in the central nervous system of the ral. I. Cell bodies and nerve terminals. Neuroscience 3: 861-943.

Matsushita, M., and Y. Hosoya (1979) Cells of origin of the spino- 
cerebellar tract in the rat, studied with the method of retrograde transport of horseradish peroxidase. Brain Res. 173: 185-200.

Mehler, W. R. (1962) The anatomy of the so-called "pain-tract" in man: An analysis of the course and distribution of the ascending fibers of the fasciculus anterolateralis. In Basic Research in Paraplegia, J. D. French and R. W. Porter, eds., pp. 26-55, Thomas, Springfield, IL.

Mehler, W. R., M. E. Feferman, and W. J. H. Nauta (1960) Ascending axon degeneration following anterolateral cordotomy. An experimental study in the monkey. Brain 83: 718-750.

Milner, T. A., T. H. Joh, R. J. Miller, and V. M. Pickel (1984) Substance $P$, neurotensin, enkephalin, and catecholamine-synthesizing enzymes: Light microscopic localizations compared with autoradiographic label in solitary efferents to the rat parabrachial region. J. Comp. Neurol. 226: 434-447.

Mitchell, J. H., M. P. Kaufman, and G. A. Iwamoto (1983) The exercise pressor reflex: Its cardiovascular effects, afferent mechanisms, and central pathways. Annu. Rev. Physiol. 45: 229-242.

Mraovitch, S., M. Kumuda, and D. J. Reis (1982) Role of the nucleus parabrachialis in cardiovascular regulation in the cat. Brain Res. 232: 57-75.

Panneton, W., and H. Burton (1985) Projections from the paratrigeminal nucleus and the medullary and spinal dorsal horns to the peribrachial area in the cat. Neuroscience 15: 779-798.

Rhoton, A. L., J. L. O'Leary, and J. P. Ferguson (1966) The trigeminal, facial, vagal, and glossopharyngeal nerves in the monkey. Arch. Neurol. 14: 530-540.

Saper, C. B. (1983) A simple, inexpensive, and reliable nanoliter syringe. Brain Res. Bull. 10: 403-405.

Shook, B. L., B. P. Abramson, and L. M. Chalupa (1984) An analysis of the transport of WGA-HRP in the cat's visual system. J. Neurosci. Methods 11: 65-77.

Snyder, R. L., R. L. M. Faull, and W. R. Mehler (1978) A comparative study of the neurons of origin of the spinocerebellar afferents in the rat, cat and squirrel monkey based on the retrograde transport of horseradish peroxidase. J. Comp. Neurol. 181: 833-852.

Tramu, G., A. Pillez, and J. Leonardelli (1978) An efficient method of antibody elution for the successive or simultaneous localization of two antigens by immunocytochemistry. J. Histochem. Cytochem. 26: 322-324.

Watson, S. J., H. Khachaturian, H. Akil, D. H. Coy, and A. Goldstein (1982) Comparison of the distribution of dynorphin systems and enkephalin systems in the brain. Science 218: 1134-1136.

Woolf, C. J., and M. Fitzgerald (1983) Properties of neurons recorded in the superficial dorsal horn of the rat spinal cord. J. Comp. Neurol. $221: 313-328$

Zemlan, F. P., C. M. Leonard, L-M. Kow, and D. W. Pfaff (1978) Ascending tracts of the lateral column of the rat spinal cord: A study using the silver impregnation and horseradish peroxidase techniques. Exp. Neurol. 62: 298-334. 